\title{
Texto e contexto para a realizacão de um projeto de dizer na produção de redações de vestibular
}

\section{Text and context for an utterance project at entrance exam essay production}

\section{Resumo}

Este artigo tem por objetivo mostrar que os atuais estudos teóricos da Linguística Textual de perspectiva sociocognitiva e interacional, ao considerarem as noções de texto e contexto como entidades inseparáveis, em uma relação de mútua constitutividade, podem colaborar para a prática pedagógica no que tange o ensino e a aprendizagem da escrita, tendo em vista o desenvolvimento da proficiência escritora.

Palavras-chave: Ensino, Produção escrita, Gênero, Contexto, Redação de vestibular.

\section{Abstract}

This article aims to show that the current Textual Linguistics theoretical studies from a sociocognitive and interactional perspective, considering the notions of text and context as inseparable entities, in a relation of mutual constituency, can collaborate to the pedagogical practice with regard to the teaching and learning of writing, in view of the writing proficiency development.

Keywords: Teaching, Writing production, Gender, Context, Entrance exam essay.

\section{Introdução}

A adoção dos Parâmetros Curriculares Nacionais (PCN), a partir da década de 1990, propiciou aos docentes subsídios para tratar o texto em sala de aula não apenas como pretexto para trabalhar aspectos 
gramaticais, mas, sobretudo, para abordá-lo em seu funcionamento e em seu contexto de produção e leitura.

Em relação à produção escrita, a orientação proposta nos PCN, ancorada na noção de gêneros, contribuiu significativamente para - avanço nas práticas escolares. Os gêneros, considerados como megainstrumentos (SCHNEUWLY; DOLZ, 2004), passaram a evidenciar o processo, e não mais o produto, no ensino e na aprendizagem da escrita; permitiram o trabalho em sala de aula com textos que circulam socialmente e estão mais próximos à realidade dos alunos; além disso, estabeleceram uma orientação metodológica que dispõe de sequências didáticas, de oferta de modelos, de processos de planejamento de texto e de reescritas.

Apesar dos avanços elencados, nossa experiência em oficinas de formação e capacitação de professores, bem como em cursos de Extensão em Educação a Distância (EAD), os relatos dos docentes revelam que a produção escrita de seus alunos apresenta problemas não só em relação ao desenvolvimento e ideias em torno de um tema de forma coesa e coerente, como também em relação à produção de sentidos em nível global. Além disso, embora os professores consigam elencar as dificuldades de seus alunos não creem que alcancem intervir de forma eficiente para que os estudantes avancem e se desenvolvam no processo de aprendizagem da escrita.

Assim, podemos inferir que os esforços empreendidos não têm alcançado os avanços esperados, conforme atestam não só os depoimentos dos docentes, mas também os resultados divulgados pela mídia quanto ao desempenho dos estudantes em relação à escrita, por exemplo, em exames de vestibular. As redações revelam que os estudantes têm dificuldade em abordar o tema proposto, em mantê-lo em foco e em assumir um posicionamento frente ao qual, desenvolvendo uma argumentação coerente com a posição assumida.
Essa realidade nos leva a concordar com a reflexão recorrente no meio acadêmico a respeito da defasagem entre as perspectivas teóricas desenvolvidas no âmbito da linguagem, da leitura e da escrita e a prática de sala de aula. Há avanços relacionados às concepções de língua, de texto e de gênero que não chegam nem aos manuais didáticos, nem ao discurso curricular.

Neste artigo, motivados por essas constatações e por nossas inquietações, advindas de nossos estudos e de nossa experiência em sala de aula no Ensino Básico, atuando como professora de Língua Portuguesa, e respaldados nos estudos da Linguística Textual, de perspectiva sociocognitiva e interacional, abordamos as noções de texto e contexto, como entidades inseparáveis, em uma relação de mútua constitutividade e o processo de produção escrita como uma situação de representação de mundo pela linguagem que viabiliza um projeto de dizer do locutor.

Acreditamos, portanto, ser possível procurar no texto as pistas contextuais necessárias e suficientes para a laboração de um projeto de dizer, considerando a interação entre produtor/ leitor, levando em conta tanto o que está explícito quanto o que está implícito. Na análise que apresentamos, partimos das expressões nominais, e destacamos a construção de objetos de discurso, o processo de ancoragem em contextos diversos para essa construção, relacionando- os ao projeto de dizer do locutor, em redações de vestibular. Adotamos a noção de objeto de discurso, conforme postulam Cavalcante e colaboradores (2010, p. 235-236), como

\footnotetext{
[...] uma criação que vai se reconfigurando não somente pelas pistas que as estruturas sintático-semânticas e os conteúdos lexicais fornecem, mas também por outros dados do entorno sociodiscursivo e cultural que vão sendo mobilizados (e negociados) pelos participantes da enunciação.
}

Consideramos, ainda, que entre as várias decisões que o produtor deve tomar para cons- 
truir a representação de objetos de discurso está a natureza das âncoras e o balizamento que faz sobre o que deixar implícito ou não em relação ao processo de ancoragem.

Buscamos, com este trabalho, enfatizar o caráter sociocognitivo e discursivo do texto e apresentar suas implicações para o ensino e a aprendizagem da produção escrita, no sentido de orientar esse processo para o desenvolvimento da proficiência escritora. Para cumprir nossos objetivos, este artigo se divide em três seções, seguidas da conclusão:

1. Apresentamos tanto a concepção de texto quanto de escrita, da perspectiva sociocognitiva e interacional, assumimos a redação de vestibular como um gênero, e salientamos que a produção de sentidos se submete a um projeto de dizer do locutor, respaldados em autores como Koch (2003); Koch e Cunha-Lima (2011), Marcuschi (2000, 2008, 2010, 2011), Morato (2011), Olson (1997), Pilar (2002), Rojo e Barbosa (2015);

2. Destacamos a noção de contexto, salientando a relação entre texto e contexto, evidenciando a importância da cognição social e da interação entre interlocutores para a produção de sentidos na produção escrita, presente nos postulados teóricos de autores como Koch (2003), Bentes e Rezende (2008), Hanks (2008), Koch, Morato e Bentes (2011) e van Dijk (2012);

3. Realizamos a análise de duas redações de vestibular, a título de exemplificação, para ilustrar como esses princípios teóricos podem orientar um novo olhar para a produção escrita de alunos que encerram a sua formação básica na escola. Para isso, destacamos a seleção das expressões nominais, a construção de objetos de discurso, o processo de ancoragem em contextos diversos para essa construção e suas implicações para a realização de um projeto de dizer, que atende a uma determinada proposta em exame de vestibular; e
4. Na conclusão, refletimos sobre as implicações de uma abordagem sociocognitiva e interacional das noções de texto e contexto, como entidades intrinsecamente ligadas em uma relação de mútua constitutividade, para o ensino e a aprendizagem da produção escrita, com vistas ao desenvolvimento da proficiência escritora no Ensino Básico.

\section{Texto, escrita e gênero, de uma perspectiva sociocognitiva e interacional}

O desenvolvimento dos estudos da cognição, da Antropologia, da Neurobiologia e da própria Linguística - nas vertentes da Etnolinguística, da Linguística Antropológica, da Sociolinguística e da Linguística Interacional -, muito contribuiu para que a Linguística Textual (LT) integrasse em sua agenda os aspectos sociocognitivos e interacionais, os quais se contrapõem à separação entre mente e corpo, entre exterioridade e interioridade, entre indivíduo e sociedade.

Assim, tomar a cognição como "um fenômeno situado" (KOCH; CUNHA-LIMA, 2011), é entender que na base da atividade linguística está a interação e o compartilhamento de conhecimentos e de atenção. Para as autoras, a atividade linguística é, pois, algo que se faz com os outros, conjuntamente ( $\mathrm{KOCH}$; CUNHA-LIMA, 2011, p. 283).

Dessa perspectiva, usar a linguagem não é apenas se dedicar a uma ação, mas entender que a linguagem se constitui como o próprio lugar em que a ação acontece, sempre em coordenação com o outro. Assentimos, assim, que compreender e definir a noção de interação é essencial para os estudos do texto no que se refere à produção de sentidos.

Vale ressaltar que as ações verbais não são realizações autônomas "de sujeitos livres e iguais", como nos advertem Koch e Cunha-Lima (2011). As linguistas asseveram que tais ações sempre se desenrolam em contextos sociais, 
com papéis sociais a serem desempenhados e com finalidades sociais. Esses aspectos evidenciam que não há neutralidade nos rituais, nos gêneros e nas formas verbais disponíveis, pois todos esses estão inseridos em dado contexto sociocultural e histórico $(\mathrm{KOCH}$; CUNHA-LIMA, 2011, p. 285).

Além disso, conforme observam Koch e Cunha-Lima (2011), a interpretação do dito, ou seja, a produção de sentidos entre instâncias e pessoas em dada interação, pode ser determinada pelo fato de as ações verbais estarem imersas em relações sociais complexas - cultural e historicamente situadas.

Salientamos, então, que contexto e interação estão estreitamente relacionados com as possibilidades de produzir sentidos, e implicados nessas, tanto na produção quanto na recepção de textos. Vale destacar, ainda, que a noção de interação e a negociação entre interlocutores, dessa decorrente, em que emerge a produção de sentidos, não se aplica apenas às práticas comunicativas on-line ou face a face, mas também às produções escritas de texto. Neste caso, interação e negociação influenciam o produtor na elaboração do texto e interferem nas ações referentes às hipóteses e projeções, ao planejamento do texto e à escolha das estratégias de que lança mão tendo em mente o seu interlocutor.

Um dos grandes avanços proporcionados pela incorporação da visada interacionista ao campo da LT está relacionado ao aspecto dinâmico que agrega às concepções de texto, de sujeito e de língua/linguagem, que não são definidos a priori, são construídos na situação concreta de produção textual. Esse aspecto ratifica as definições de texto como processo, de sujeito/produtor/leitor de textos como ator/ construtor social e a concepção de língua/linguagem como "[...] heterogênea, social, histórica, cognitiva, indeterminada, variável, interativa e situada" (MARCUSCHI, 2008, p. 65).

O texto constitui-se, então, como o lugar da interação capaz de viabilizar representações do mundo, em um movimento ao mesmo tempo de transformação do que é representado e de reconstrução do próprio dizer. Nesse sentido, transforma-se também a relação entre texto e contexto, que ultrapassa a visão de interioridade e exterioridade e coloca em evidência a mútua influência entre os quais, tal como veremos adiante, na segunda seção deste artigo.

Cavalcante e colaboradores (2010, p. 228) apresentam uma definição de texto que retrata a concepção desse objeto de estudo no campo da LT; atualmente:

[...] o texto é a unidade funcional que não somente permite a interação, como também viabiliza diversas formas de representar o mundo, de transformá-lo e de a um só tempo, reconstruir-se a partir dessa dinâmica emergência dos sentidos, que envolve toda espécie de heterogeneidades enunciativas, dentre elas as relacões intertextuais e interdiscursivas.

Nessa direção, Bazerman (2006) observa que a escrita nos fornece os meios pelos quais deixamos traços de nossa existência, nossas condições de vida, nossos pensamentos, nossas ações e intenções. Para esse autor, a escrita torna a nossa presença real em um mundo social, possibilitando-nos imprimir a marca de nossas necessidades e de nosso valor.

Encontramos também nos estudos de Olson (1997) que os atos de leitura e escrita se transformam, uma vez que requerem atividades cognitivas e interacionais para interpretar e fazer significar o que não está expresso e explicitamente grafado. Para ler é preciso reconhecer as pistas de como os textos devem ser entendidos; para escrever é preciso aprender o controle do que se deve deixar explícito ou não, tais como as marcas na superfície textual. Para Olson (1997, p. 268), “[...] ler e escrever oferecem oportunidades para corroborar a prática de determinar a força e a estrutura dos textos, tanto quando elas são explícitas como quando precisam ser inferidas".

Esses dois postulados estão em consonância com o que admitimos em relação ao 
sujeito do fazer textual, que o torna um sujeito complexo, determinado e mobilizado do ponto de vista sociocultural para atuar por meio da linguagem. Além disso, é no ato de escrever que esse sujeito pensa sobre o uso da língua de maneira consciente e, assim, transforma-se em um estrategista, que, em suas escolhas, considerará tanto os conhecimentos linguístico, textual e de mundo que possui, quanto a situação de comunicação, o interlocutor e os propósitos comunicativos.

Assim, compreendemos como o domínio da escrita pode ser decisivo para a inserção do sujeito como ator social, capaz de se posicionar e interagir com o seu entorno, dada a relevância da escrita para as práticas sociais em um mundo interligado e mediado por novas Tecnologias de Informação e de Comunicação (TIC).

Vale lembrar ainda que a escrita e os sentidos propostos se manifestam, conforme assevera Marcuschi (2008, p. 154), "[...] sempre por meio de textos realizados em algum tipo de gênero". No entanto, dominar um gênero, observa esse autor, não é domar uma forma linguística; trata-se, antes, de "[...] realizar linguisticamente objetivos específicos em situações sociais particulares" (MARCUSCHI, 2008, p. 154). Assim, Marcuschi (2008) salienta que o estudo dos gêneros é uma fértil área interdisciplinar que permite trabalhar tanto o funcionamento da língua quanto as atividades culturais e sociais.

Essa noção de gênero nos remete ao uso da linguagem em práticas sociais de escrita em que se revela uma interlocução, marcada social e historicamente, em dada situação de comunicação. Tomamos, assim, os gêneros na acepção do filósofo russo Mikhail Bakhtin (2000), para quem são formas relativamente estáveis de enunciados, marcadas social e historicamente, ligadas a diferentes esferas da atividade humana.

Como ressaltam Rojo e Barbosa (2015), as esferas de atividades não são entendidas por Bakhtin de maneira estática ou estanque, pois se transformam com as mudanças históricas, sociais e culturais, além do que estão estrei- tamente relacionadas e sofrem influências mútuas. A finalidade, o funcionamento e a especificidade da esfera em seu tempo e lugar históricos determinam as características do gênero no que este tem tanto de estável como de flexível.

Tomar a ideia de gênero sempre ligada ao uso e à atividade social é inclui-la no meio educacional como uma forma de tornar os textos em circulação na escola menos didatizados, o que significa levar para a esfera escolar textos de domínios sociais, tal como ressalta Marcuschi (2010).

De acordo com Marcuschi (2011), há significativa variedade de estudos sobre os gêneros, mas, por ser o gênero essencialmente flexível e variável, tal como a linguagem, aqueles que privilegiam a forma e estrutura perdem sua força. Para esse autor, "[...] assim como a língua varia, também os gêneros variam, adaptam-se, renovam-se, multiplicam-se" (MARCUSCHI, 2011, p. 19).

Tal flexibilidade e variabilidade dos gêneros possibilitam investigar entre as situações de comunicação, nas atividades de comunicação verbal institucionalizadas e recorrentes, novos "[...] tipos temáticos, composicionais e estilísticos de enunciados/textos [...]" (ROJO; BARBOSA, 2015, p. 64). Nas palavras de Marcuschi (2011, p. 19), o gênero é "[...] uma 'ação social tipificada' que se dá na recorrência de situações que tornam o gênero reconhecível".

Com base nesse aporte teórico-metodológico, neste trabalho tomamos a redação de vestibular como um gênero, uma vez que tem caráter recorrente nos exames vestibulares que ocorrem anualmente, em diferentes universidades, para avaliar a proficiência escritora de candidatos ao Ensino Superior. Consideramos, então, respaldados por Pilar (2002), que a redação de vestibular constitui um gênero, pois possui uma função em um contexto específico, o qual se determina tanto por um objetivo comunicativo, quanto pela interação estabelecida entre produtor e interlocutor, neste caso, estudante e professor, respectivamente. 
O gênero redação de vestibular, dessa perspectiva, situa-se em uma esfera de atividade educacional, institucional e pública; quanto à função e intenção, é designado, basicamente, pela exposição do posicionamento do produtor frente a um tema proveniente do cotidiano, geralmente relevante no contexto social e cultural, e pelo desenvolvimento de uma argumentação concernente à posição assumida; quanto ao estilo, determina o uso da língua em seu registro formal, expresso pela norma culta; quanto à forma composicional, conta com a presença de sequências tipológicas dissertativas e argumentativas, que compõem o plano global.

Vale lembrar que, no gênero, a relevância do estilo e da estrutura composicional está em fazer ecoar os sentidos e o tema, dois componentes que "[...] carregam em suas marcas linguísticas e textuais as apreciações valorativas do locutor/autor [...]" (ROJO; BARBOSA, 2015, p. 94). Desse modo, compreendemos ser importante, nas redações de vestibular, levar em conta a imagem que o produtor-estudante tem do professor-interlocutor e a representacão que constrói do tema a ser tratado.

Reconhecer a redação de vestibular como um gênero permite inseri-la nas atividades de produção escrita, no período de Escolarização Básica, como um instrumento de ação social, uma forma de prática social que decorre da vontade e/ou necessidade que os sujeitos têm de conquistar novos espaços na sociedade (PILAR, 2002).

Entendemos, ainda, que considerar a redacão de vestibular um gênero é uma forma de evidenciar as características sociocomunicativas e textual-discursivas presentes nessa prática de produção escrita rotineira na vida dos estudantes, principalmente nos últimos anos da Educação Básica.

Essas considerações evidenciam que a abordagem dos gêneros na escola deveria caracterizar-se, como orientam os PCN, por uma sistematização coerente e por uma reflexão sobre os papéis dos interlocutores, sobre os objetivos do texto e acerca das estratégias necessárias para lê-lo/produzi-lo (GOMES-SANTOS et al., 2010, p. 324).
Como exposto, o gênero redação de vestibular envolve o tipo dissertativo-argumentativo, sendo designado, basicamente, pela função e intenção de apresentar a exposição e o posicionamento do produtor frente a um tema específico e desenvolver uma argumentação concernente à posição assumida.

Neste trabalho, tomamos a noção de argumentação, de acordo com Cavalcante, Custódio Filho e Brito (2014, p. 112), "[...] como uma troca de ideias que o sujeito utiliza para defender um ponto de vista, ' com argumentos fundamentados ou com fins manipulatórios".

Relacionamos, ainda, a questão da argumentatividade ao postulado da não neutralidade no uso da linguagem. Ou seja, toda vez que no processo de referir o mundo, um locutor faz uma escolha frente a diferentes possibilidades de que a linguagem dispõe, indica uma direção argumentativa a seu dizer, posicionando-se frente a um "objeto do mundo".

Assim, consideramos que o processo de produção escrita das redações de vestibular configura-se como uma situação de representação de mundo pela linguagem, que envolve não apenas os conhecimentos linguísticos do produtor, mas também os seus saberes de mundo, socioculturais e textuais, os quais remetem aos diferentes contextos envolvidos, em distintos níveis. A ideia plural de contextos e a sua relação de mútua constitutividade com o texto é o que apresentamos na segunda parte deste artigo.

\section{A relação texto e contexto e suas implicações para a produção escrita}

Neste trabalho, adotamos a noção de contexto não só como algo externo e dado a priori

1 Entendemos ponto de vista, neste artigo, como o posicionamento que o produtor de texto deve tomar frente a um dado tema, como ocorre nas redações de vestibular, em que o candidato é instado a tomar um partido frente a uma questão polêmica e se colocar favorável ou não a ela. Não se trata de Ponto de Vista (PDV) relacionado à responsabilidade enunciativa (ADAM, 2008); nem à polifonia, conceito bakhtiniano, das várias vozes que se apresentam em um texto, imprimindo diferentes perspectivas sobre um mesmo fato de realidade. 
- entorno circunstante, ambiente ou situação comunicativa, circunstância histórico-cultural -, mas também como algo construído no momento da interação, "[...] sendo continuamente alterado e ampliado, concorrendo para isso o cotexto, a situação comunicativa, as ações interacionais e determinações socioculturais e históricas que passam a fazer parte do domínio cognitivo de cada um dos interlocutores" $(\mathrm{KOCH}$, 2003, p. 24). Dessa perspectiva, a relação entre contexto e linguagem "é de mútua constitutividade"," isto é, tanto o contexto determina o uso da linguagem como o uso da linguagem determina e estabelece o contexto.

De modo a tratarmos dessa noção, valemo-nos, principalmente, dos trabalhos de van Dijk (2012), de perspectiva sociocognitiva e interacional, e das pesquisas de Hanks (2008) segundo a abordagem da Linguística Antropológica. Nos postulados teóricos desses autores, encontramos pressupostos, determinações e categorias que subjazem ao que definem como contexto e a sua relação com a produção de sentidos, no âmbito da produção e recepção de textos.

Van Dijk (2012) defende a seguinte tese, que acredita ser crucial para compreender o que é contexto e como se relaciona ao discurso: "[...] não é a situação social que influencia o discurso ou é influenciada por ele, mas a maneira como os participantes definem essa situação" (VAN DIJK, 2012, p. 11).

Vale ressaltar que na tese defendida pelo linguista estão implicadas as noções de cognição social e de interação, que permeiam a sua concepção de contexto, impingindo-lhe uma característica dinâmica de processo e não estática de pano de fundo. Desse modo e de acordo com van Dijk (2012, p. 11), os "[...] contextos não são uma condição objetiva ou de causa direta, mas antes construtos (inter)subjetivos concebidos passo a passo e atualizados na interação pelos participantes enquanto membros de grupos e comunidades".

2 A expressão mútua constitutividade, presente no texto de Koch, Morato e Bentes (2011, p. 86), refere-se à "[...] solidariedade constituída entre língua e mundo social [...]".
A concepção de Van Dijk abarca, pois, tanto o caráter de unicidade de cada texto/conversa, quanto as bases comum e social de representações sociais e conhecimentos compartilhados dos interlocutores. O autor defende que "[...] se os contextos fossem condições ou restrições sociais objetivas, todas as pessoas que estão na mesma situação social falariam do mesmo modo" (VAN DIJK, 2012, p. 11).

Vale observar que, no âmbito escolar, muitas vezes os professores têm essa expectativa em relação à produção escrita de seus alunos. Assim, entendemos que ampliar a noção de contexto e assimilá-lo como processo significa ampliar as possibilidades de atribuir sentidos aos textos discentes, de compreender as suas especificidades e interagir com o produtor do texto de maneira mais cooperativa.

Van Dijk (2012) destaca que a sua perspectiva é sociocognitiva, pois o seu propósito é integrar as abordagens cognitivas do texto e da fala em um único quadro teórico coerente, considerando tanto as estruturas sociais e as situações também sociais - teoria social do discurso -, quanto os componentes cognitivos, não apenas os relativos às condições sociais compartilhadas - conhecimentos, ideologia, normas, valores, crenças -, como também os modelos mentais únicos dos sujeitos sociais.

Esses postulados indicam o quanto a noção de contexto, da perspectiva sociocognitiva, agrega tanto a ideia de entorno, de situação imediata e das determinações e condições socioculturais e históricas, quanto a de modelos mentais, de representações sociais compartilhadas e de situação mediata - contexto.

Nas palavras de Koch, Morato e Bentes (2011, p. 85), essa noção mais atual do conceito de contexto dilui "[...] as dicotomias linguístico/extralinguístico, cognição individual/social, memória semântica/episódica [...]" e permite "[...] evidenciar os fatores condicionantes socioculturais e ideológicos articulados de maneira constitutiva às situações interacionais concretas [...]".

Assim, ultrapassada a ideia dicotômica de interioridade e exterioridade, antes correlacio- 
nada a contexto, temos a ideia plural de contextos que dependem, para serem construídos, da inter-relação entre situações comunicativas sociais e da atuação dos interlocutores, tendo em vista os seus conhecimentos compartilhados, as suas intenções, propósitos e objetivos.

Tanto é assim que, conforme observa Koch (2003), os interlocutores podem desenvolver estratégias para o processamento eficaz do texto e para a seleção apropriada do contexto. Para van Dijk (2012), os contextos, com frequência, são amplamente planejados, não são construídos do zero no momento da interação - ou seja, os participantes conhecem previamente e planejam prospectivamente muitas das propriedades da situação comunicativa, ao saber com quem, quando e onde vão se comunicar e com que objetivos. Esse aspecto é relevante para textos escritos e formais, por isso, de acordo com o autor, da mesma forma que é possível aprender gêneros discursivos, é possível aprender tipos de contexto.

A ideia formulada por esse teórico de que é possivel propor o ensino e a aprendizagem de tipos de contexto como já se faz com gêneros, a nosso ver, é uma proposta a ser considerada e aplicada ao ensino e à aprendizagem da escrita, pois conceber o contexto do ponto de vista sociocognitivo enfatiza o papel atuante do produtor de texto como sujeito social, além do que, oferece instrumentos e estratégias para a ação reflexiva sobre a situação de comunicação, acerca dos propósitos comunicativos e sobre a adequação do uso da linguagem, fomentando, assim, o desenvolvimento do estudante como produtor de texto proficiente.

Na mesma direção de van Dijk (2012), mas pela perspectiva da Linguística Antropológica, Hanks (2008) sublinha a relação entre linguagem e contexto como um dos focos centrais da pesquisa sobre linguagem nas últimas décadas, destacando a importância do contexto "[...] tanto como fator restritivo quanto como produto do discurso que conduz a um refinamento das abordagens da fala, pois é principalmente na elaboração de enunciados falados ou escri- tos que linguagem e contexto são articulados" (HANKS, 2008, p. 169).

De acordo com Hanks (2008), é necessário entender que o conceito de contexto é baseado em relações, e saber como é tratado esse conceito depende de como são construídos elementos fundamentais como língua(gem), discurso, produção e recepção de enunciados, práticas sociais, entre outros.

Assim, para lidar tanto com as especificidades semióticas das práticas discursivas quanto com o seu encaixamento social e histórico, Hanks (2008) propõe duas dimensões abrangentes do contexto, as quais esse autor denomina emergência e incorporação/encaixamento.

A primeira dimensão - emergência - diz respeito a aspectos do discurso que surgem da produção e recepção como processos em curso. Refere-se, portanto, à atividade mediada verbalmente, à interação, copresença, temporalidade, em contexto restrito, mas marcado em termos fenomenológicos, sociais e históricos. Já a incorporação/encaixamento designa a relação entre aspectos contextuais relacionados ao enquadramento do discurso, à sua centração em quadros teóricos sociais e históricos mais amplos (HANKS, 2008, p. 176-178).

Para melhor compreender essas duas dimensões, apoiamo-nos em Bentes e Rezende (2008). Para esses autores, compreender as duas dimensões requer se apropriar de uma primeira diferenciação que Hanks (2008) faz entre dois níveis contextuais: situação e cenário. O primeiro nível é um espaço de monitoramento mútuo entre indivíduos copresentes, que existe como potencialidade, minimamente estruturado e naturalmente anterior a qualquer enunciado. A situação é um tipo de "exterior a priori" no interior do qual a fala e linguagem são projetadas. Mas é necessário acrescentar à situação social os julgamentos dos participantes sobre o que é relevante e acerca do que acontece no "aqui e agora" estabelecidos. Isso define a passagem de situação a cenário, o segundo nível (BENTES; REZENDE, 2008, p. 38). 
No caso do primeiro nível, a situação, por estar definido "a priori", é possível ao sujeito produtor de texto analisá-la e adaptar-se à qual para adequar suas escolhas, planejar as próprias estratégias, no intuito de atender às expectativas do leitor e da própria situação comunicativa. No nível do cenário, é exigido do produtor do texto que se preocupe em compartilhar com o interlocutor os seus conhecimentos prévios, as suas representações sociais, em esclarecer as suas intenções e propósitos, oferecendo sinalizações - pistas contextuais - suficientes para que o leitor realize as inferências de maneira satisfatória com vistas à produção de sentidos.

Além disso, conforme observam Bentes e Rezende (2008), Hanks (2008) incorpora ao nível da emergência um campo semiótico de natureza simbólica e indexical/demonstrativa sobre contexto. Nesse campo, todos os traços do cenário são transformados pelos signos - simbólicos, indiciais e icônicos -, pelas relacões entre os quais - sintáticas, semânticas, pragmáticas -, pela manutenção de objetos e por várias funções, incluindo a referência e orientação da atenção do interlocutor por meio de palavras - e podemos acrescentar por marcas gráficas e outros artifícios -, no caso da modalidade escrita, através de gestos - e podemos acrescentar por meio de entonações, altura de voz etc. -, no caso da modalidade oral.

Assim, o cenário interativo converte-se em campo de signos e, em seu interior, os enunciados - textos -, em suas dimensões simbólica e indicial, transformam o contexto. Ao orientar a atenção dos participantes, tematizar os objetos de referência, os quais, enunciados, formulam, invocam e constroem o contexto. Conforme asseveram Bentes e Rezende (2008), é importante observar que, segundo Hanks (2008), o campo semiótico é a unidade contextual mínima com base na qual se pode produzir qualquer análise dos fenômenos da linguagem que considere o contexto.

Destacamos ainda que, para analisar a relação texto e contexto, de acordo com Bentes e Rezende (2008), é importante reafirmar o prin- cípio básico da perspectiva teórica de Hanks: a linguagem não é nem a causa nem a medida do mundo tal qual vivemos. Assim, no estudo do contexto, "[...] dever-se-ia considerar que os enunciados (ou textos) não são os elementos a partir dos quais todo o contexto se organiza, mas verdadeiramente constituem a interação entre a linguagem, a cultura e o mundo individual vivido pelos sujeitos" (BENTES; REZENDE, 2008, p. 42).

Essa perspectiva permite que, na análise de um texto inserido em uma prática social e em uma dada situação comunicativa, possamos vislumbrar todos os aspectos emergenciais implicados: o exterior, dado a priori; o interior, no qual a linguagem é projetada; o julgamento dos participantes sobre o que é relevante e seus conhecimentos prévios e as semioses que envolvem os enunciados em dado cenário. Além disso, ao observar os três níveis emergenciais e as suas relações, podemos agregar à análise aspectos sociais e históricos mais amplos, tais como imposições de papéis, lugares e funções que os sujeitos podem - ou devem - assumir ou aos quais deve se submeter.

Assumir o contexto não apenas como o entorno ou como algo dado a priori, não apenas como um conjunto de conhecimentos prévios e vivências do locutor/produtor, mas como algo construído por todos esses elementos na relação com o outro, que traz também para a interação, sempre situada, os seus conhecimentos e as suas vivências e influências da posição que nessa ocupa, conduz tanto a um novo olhar sobre a produção e recepção de sentidos dos textos e sobre a própria concepção de texto quanto a novas possibilidades de análise e reflexões sobre as práticas de linguagem.

Assentimos, assim, respaldados nos referenciais teóricos apresentados, que os contextos e a especificidade da interação entre os participantes interferem nas escolhas do produtor tendo em vista o seu desejo de atender a uma proposta de produção escrita, como é o caso das redações de vestibular. Quanto mais o produtor tiver conhecimento e mantiver presente em sua mente os aspectos dos diversos con- 
textos e as especificidades da interação com o seu interlocutor, além da mútua influência que sofrem e exercem texto, contexto e sujeitos em interação, mais chances terá de adequar a sua ação para atender às expectativas da situação de produção escrita e viabilizar um projeto de dizer. É o que destacamos, a seguir, nas análises de duas redações de vestibular, a título de exemplificação.

\section{Texto e contextos: viabilizando um projeto de dizer em redações de vestibular}

Assumimos, neste trabalho, a redação de vestibular como um gênero, que circula na esfera didático-educacional, constituindo-se como um exemplar de texto autêntico, elaborado por produtores ainda não proficientes, estudantes ao final da Escolarização Básica. Esse gênero é produzido em uma situação real de produção escrita, para avaliação e promoção acadêmica, inserido, portanto, em uma prática social institucionalizada e recorrente.

Além disso, é um gênero designado, basicamente, pela função e intenção que o caracterizam, isto é, pela exposição do posicionamento do produtor frente a um tema específico, atual e de relevância social, e o desenvolvimento de uma argumentação concernente à posição assumida. A própria função que designa o gênero redação de vestibular, portanto, propõe um diálogo com o pensamento do outro. Tais especificidades oferecem elementos que auxiliam na configuração dos contextos envolvidos e na interação estabelecida entre os interlocutores.

Para a análise, a título de exemplificação, tomamos duas redações do exame de vestibular da PUC-SP, em sua edição de 2014, cujo tema é o anonimato na internet. A proposta envolve um texto de referência e a comanda, isto é, a proposta propriamente dita, que se compõe de algumas orientações quanto à forma de desenvolver o texto solicitado, aos procedimentos necessários e critérios de avaliação.
O texto de referência consiste em um artigo de opinião, escrito pelo jornalista Eugênio Bucci, que circula em seu blog A Varanda, intitulado Cyberanonimato. Adaptado para a proposta do exame de vestibular da PUC-SP, 2014, esse texto de referência e a proposta de redação encontram-se, na integra, disponíveis em: <http:// www.cpv.com.br/cpv_vestibulandos/redacoes/ puc/PUCSP_2014.pdf> (acesso em: 25 abr. 2016).

Vale destacar como positivo nessa proposta tanto a adequação do tema, por estar vinculado e próximo à realidade dos jovens dessa faixa etária, quanto o texto de referência. Este último possibilita uma reflexão ao expor argumentos a favor e contra o anonimato na internet, conferindo maior liberdade para o candidato posicionar-se, concordando ou discordando, levando em conta os seus conhecimentos prévios e vivências.

Atestamos, conforme exposto neste artigo, que os contextos e a especificidade da interação entre os participantes interferem nas escolhas do produtor tendo em vista o seu desejo de atender a uma proposta de produção escrita. Como afirmamos, quanto mais o produtor tiver conhecimento e mantiver presente em sua mente os aspectos dos diversos contextos e as especificidades da interação com seu interlocutor, além da mútua influência que sofrem e exercem texto, contexto e sujeitos em interação, mais chances terá de adequar a sua ação para atender às expectativas da situação de produção escrita.

Adotamos a ideia plural de contextos que dependem, para serem construídos, da inter- relação entre situações comunicativas sociais e da situação dos interlocutores, considerando os seus conhecimentos compartilhados, as suas intenções, os seus propósitos e objetivos. Assim, consideramos na análise das redações os contextos, mais amplo e imediato, e a especificidade da interação entre um produtor, candidato aspirante à universidade e um leitor, professor/avaliador.

Como contexto mais amplo definimos uma esfera educacional, institucional e pública de 
avaliação, em que a redação de vestibular está inserida, que ocorre anualmente, em algumas instituições mais de uma vez por ano, e são voltadas para a seleção de candidatos que almejam continuar os seus estudos no Ensino Superior.

Essa prática se dá há mais de três décadas, constituindo-se a redação de vestibular como uma ação social tipificada que, por sua recorrência, torna-a reconhecível, além de se constituir como objeto de ensino e aprendizagem da escrita, sobretudo nos três anos finais da Escolarização Básica e nos cursinhos preparatórios ao vestibular.

Desse modo, a assunção da redação de vestibular como um gênero, assim como a sua inserção nesse campo social também determinam os seus propósitos - funções, intenções e interesses -, além de evidenciar a posição, os poderes, deveres e valores dos indivíduos que nesse atuam.

Essas são condições que colaboram para que o produtor de texto lance mão de seus conhecimentos prévios textuais, linguísticos, de experiências da prática vivida na Escolarização Básica e de sua bagagem sociocultural para proceder à elaboração da redação de vestibular. O perfil que delineamos ao produtor é o de um sujeito situado social e historicamente, inserido em dada comunidade, que tem como propósito atender à proposta de maneira bem-sucedida.

Configura-se, assim, o contexto mais amplo, dado a priori, dessa prática social, em que estão implicados os aspectos socioculturais e históricos que influenciam o contexto mais imediato, isto é, a situação autêntica de produção escrita.

Outrossim, consideramos que a comanda do exame e o texto de referência, disponibilizados pela instituição ao candidato produtor do texto, configuram o contexto imediato, importante e balizador. Tanto a comanda como o texto de referência desempenham o papel de estabelecer determinações e trazer informações das quais o produtor lança mão para elaborar a redação e servem de parâmetros para a avaliação pelo professor-avaliador.

Por um lado, consideramos o artigo de opinião como um componente do contexto mais imediato, por servir ao candidato como exemplo de proposta de argumentação, como repertório de informações e como fonte de possíveis valorações emitidas por um produtor proficiente que assume determinado posicionamento frente ao tema.

Por outro, a comanda evidencia que o produtor do texto sabe, de antemão, que deve dissertar sobre um tema e explicitar o seu posicionamento frente a esse no texto, além de desenvolver argumentos para defender a sua tomada de posição. A orientação pontua, ainda, que o candidato deve utilizar a norma culta e construir um texto com clareza, coesão e coerência, critérios pelos quais o seu texto será avaliado. Dessa forma, o produtor pode planejar e desenvolver estratégias para o processamento eficaz do texto e para a escolha apropriada de dados dos contextos, imediato e mais amplo.

Quanto à especificidade da interação entre os interlocutores, temos de um lado, o professor-avaliador, leitor proficiente, que avalia, seleciona e classifica; de outro, o candidato-produtor, ainda não proficiente, que se submete à avaliação, seleção e classificação e que está imbuído do desejo de ser aprovado. Configura-se, assim, um contexto intersubjetivo atualizado na interação que ocorre entre o candidato ao exame de vestibular, estudante egresso da Educação Básica, e o professor- avaliador, profissional docente que compõe a banca avaliadora do exame, ambos situados sociocultural e historicamente no contexto mais amplo.

Atestamos, ainda, que os sujeitos envolvidos nessa interação ocupam posições hierárquicas em níveis diferentes, não se conhecem e não têm proximidade. Destacamos, pois, que a posição e os papéis que os interlocutores assumem nessa interação, por serem mais fortemente marcados hierarquicamente, não 
funcionam como um fator facilitador para o produtor do texto, pois não se delineia, de antemão, a interação colaborativa do leitor, por ser um professor-avaliador. Assim, para proceder às suas escolhas, o produtor conta apenas com pressuposições sobre o perfil desse leitor proficiente, os seus conhecimentos, as suas crenças, julgamentos, ideologias e sobre as suas expectativas e o grau de exigência como professor-avaliador.

Com base nos aspectos apresentados, podemos confirmar que os contextos podem ser planejados e não são construídos a partir do zero, no momento da interação. O conhecimento da esfera de atividade-educacional e institucional-, do tema-a partir de suas experiências e de sua bagagem sociocultural-, do propósito e das características do gênero redação de vestibular, da comanda e do texto de referência oferecidos pelo exame de vestibular, bem como do perfil do leitor, o professor-avaliador, concorre para o planejamento prévio do produtor, que visa tanto ao atendimento da proposta, quanto à validação do leitor, tendo em vista a sua aprovação.

A configuração dessa situação de avaliação confirma que o candidato tem uma disposição prévia e bem estabelecida de atender a proposta de produção escrita de maneira bem-sucedida. Como produtor do texto, deve considerar, na elaboração de sua redação, tanto as determinações e os fatores condicionantes dos contextos, quanto o perfil de seu interlocutor, um leitor proficiente e avaliador. Todos esses aspectos influenciam em suas escolhas linguísticas e estratégias textual-discursivas para viabilizar um projeto de dizer.

Ao cotejar as duas redações, o nosso intuito é mostrar como, para construir representações para um objeto de discurso, no caso "anonimato na internet", o tema da redação, e expor um posicionamento frente ao qual, orientando argumentativamente o texto, o produtor buscará a ancoragem nos contextos imediato e mais amplo, deixando, ou não, pistas de sentido suficientes no texto, a fim de negociar os sentidos com o seu interlocutor e viabilizar o seu projeto de dizer.

Partimos da seleção das expressões nominais, que explicitam uma valoração positiva ou negativa do produtor ao construir representações para o objeto de discurso anonimato na internet; identificamos a ancoragem nos contextos, imediato e mais amplo, para a construção dessas representações e observamos a presença ou ausência das pistas de sentido deixadas pelo produtor no texto. Além disso, relacionamos esse processo à exposição do posicionamento do produtor frente ao tema, à orientação argumentativa desenvolvida, para analisar em que medida colaboram para a viabilização de um projeto de dizer e para o atendimento da proposta de produção escrita do exame de vestibular

Selecionamos duas redações para ilustrar a análise, sendo três excertos de cada uma das quais: um exemplo bem-sucedido - Redação 1 - e outro não tão bem-sucedido - Redação 2 -, no que diz respeito à explicitação do posicionamento do produtor frente ao tema central, à orientação argumentativa coerente a esse posicionamento, à viabilização de um projeto de dizer e, consequentemente, ao atendimento efetivo à proposta. Ressaltamos, ainda, na análise realizada, como o produtor interage com o leitor compartilhando conhecimentos, realizando ancoragens em diferentes contextos, sugerindo-lhe pistas e delineando, assim, um caminho para a produção de sentidos. A seguir, apresentamos os trechos selecionados de cada redação e sua respectiva análise:

Redação 7 (R7)

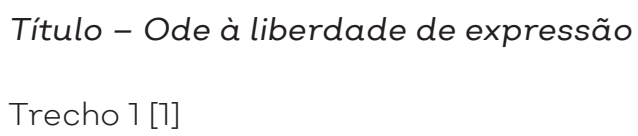

Título - Ode à liberdade de expressão Trecho $1[1]$

Desconfiança e insegurança. É o que sentiria um comprador online se o seu fornecedor não tivesse nome nem endereço. Quem confiaria? $\bigcirc$ anonimato, embora tenha sido utilizado com ótimas finalidades em algumas épocas e lugares, até em épocas de Ditadura e repressão, hoje, 
está aliado, principalmente na internet, a ferir imagens, denegrir e até a práticas de crimes mais pesados. Por isso, há que se fazer uma reflexão acerca do assunto e saber o objetivo e uso deste, garantindo sempre o respeito alheio, integridade e dignidade das pessoas a quem este recurso atinge.

Trecho 2 [2]

Em outros tempos, crimes de tão "fácil acesso" como hoje, não eram possíveis. A comunicabilidade era bem menor e até certa época tudo estava confinado à Igreja e ao dogmatismo religioso. Muitos filósofos iluministas, para criar e disseminarem suas ideias e ideais utilizavam-se do anonimato para não irem à forca, guilhotina.

Trecho 3 [3]

[...] mas a realidade, sim, é. Além dos atos e crimes contra a dignidade, como xingamentos, mentiras, preconceito, homofobia, há também aqueles de maior peso, com a venda e tráfico das drogas anônimo, além dos canais intranet, onde existem incontáveis formas de crimes anônimos: venda de pessoas, armas, droga e até "dicas" de suicídio e assassinato.

Nos trechos selecionados da R1, observamos que o produtor apresenta para o objeto de discurso anonimato na internet, representações de valoração tanto positiva quanto negativa. Destacamos o valor positivo nos trechos sublinhados em [1] e [2], e o valor negativo nos trechos em itálico em [1] e [3]. Para construir essas representações, o produtor recorre a ancoragens nos contextos imediato e mais amplo, como veremos a seguir.

Nos trechos sublinhados em [1] e [2], podemos observar a representação construída para anonimato como recurso utilizado para conseguir a liberdade, com valoração positiva. Para elaborar essa representação, o produtor apoia-se em dados do contexto imediato [2], o artigo de opinião, referindo-se aos feitos de John Locke, filósofo iluminista, citado no artigo, que usou do anonimato para lutar por seus ideais e pela liberdade; mas também recorre a dados do contexto mais amplo [1], remetendo a seus conhecimentos, e talvez vivências, sobre períodos de restrições às liberdades democráticas no Brasil. As expressões nominais "ditadura e repressão", "filósofos iluministas", "disseminar ideias e ideais" são pistas de sentido para essas ancoragens em contextos distintos.

Já nos trechos em itálico, inicialmente em [1], para construir a primeira representação para anonimato na internet, apresentada no texto, o produtor evoca uma situação de "compra online", atribuindo-lhe valoração negativa, ao atrelá-la aos sentimentos de desconfiança e insegurança por parte de um comprador. Para construir essa representação, o produtor remete a dados do contexto mais amplo, a sua bagagem sociocultural, suas vivências sobre as questões de segurança e credibilidade em situações de compras on-line, que são ações ordinárias na internet e de conhecimento público. As expressões nominais "comprador online", "desconfiança" e "insegurança" oferecem pistas de sentido para essa ancoragem. O produtor, nesse caso, compartilha conhecimentos de práticas na internet com o seu interlocutor que acredita, por hipótese, que também os possua, negociando sentidos.

As outras duas representações para anonimato na internet, em [1] e [3], como recurso para ações nocivas, de valoração negativa, ancoram de duas maneiras diferentes: na primeira [1], a ancoragem se dá no contexto imediato, o artigo de opinião, em que o jornalista cita $\circ$ uso do anonimato na internet para enxovalhar a honra alheia; as expressões nominais "ferir imagens" e "denegrir" são as pistas de sentido para essa ancoragem; na segunda [3], o produtor recorre a dados do contexto mais amplo, a seus conhecimentos e vivências sobre fatos e ações que ocorrem na realidade virtual, bastante divulgados na própria mídia virtual, de conhecimento público. As expressões nominais "xingamentos, preconceito, homofobia", entre outras, oferecem as pistas de sentido para essa ancoragem. Nesse caso, mais uma vez, o produtor compartilha conhecimentos e vivências 
de práticas na internet com o seu interlocutor, contando, portanto, com uma atitude colaborativa de sua parte - do interlocutor -, que deve evocar as suas vivências e os seus conhecimentos na internet e utilizá-los como âncoras para realizar as inferências necessárias para produzir sentidos.

Podemos observar, na tratativa dada ao tema pelo produtor, nesses trechos, uma tendência a se posicionar desfavoravelmente em relação ao anonimato na internet. Essa disposição será confirmada no desenvolvimento do texto, pois o produtor destaca a valoração positiva sobre o anonimato, apenas para contrapor-se a essa, em seguida, como ocorre no trecho [1].

A construção da representação do objeto de discurso anonimato na internet, elaborada no texto, aponta para o fato de que o produtor, para estabelecer no texto o seu posicionamento desfavorável frente ao tema e orientar a sua argumentação, conta com a atitude colaborativa na interação com o seu interlocutor, e recorre não só a dados do contexto mais amplo, tanto seus conhecimentos e vivências quanto os de seu interlocutor, como também a dados do contexto imediato, como é o caso do artigo de opinião, componente de referência na proposta do exame de vestibular, acessível a ambos.

Sustentamos, portanto, que o produtor se sai bem em sua redação ao delinear pistas de sentido, ao estabelecer uma interlocução colaborativa com o seu leitor, por meio de ancoragens em diferentes contextos e da negociação na interação para a produção de sentidos, ao explicitar o seu posicionamento frente ao tema e ao desenvolver uma orientação argumentativa coerente, viabilizando, assim, o seu projeto de dizer - "[...] embora possa ser considerado um assunto que leva à reflexão, o anonimato na internet como recurso para crimes deve ser punido e 'findado', pois sua má utilização traz prejuízos à liberdade individual [...]" - atendendo, portanto, à proposta do exame de vestibular de maneira bem-sucedida.

Redação 2 (R2)

Título - A loucura de Sartre

Trecho 1 [1]

O mundo "on line" é formado por anônimos que atuam como desejam e causam danos ao próximo sem serem devidamente punidos.

Trecho 2 [2]

As leis são essências para a manutenção da liberdade, fato defendido pelos filósofos contratualistas: Locke e Hobbes. Voltaire, com o Espírito das Leis, pregou a tripartição dos poderes por ter consciência do caráter abusivo do homem. O ser, quando pode fazer algo sem ser julgado ou condenado se torna um déspota. E é isso que o anonimato da web faz com o indivíduo atual.

Trecho 3 [3]

A internete trouxe diversos benefícios à humanidade como a integração e a liberdade mas tal ferramenta deve ser utilizada com cautela é responsabilidade e, atualmente, isso não acontece.

Nos trechos selecionados da R2, observamos que o produtor constrói para o objeto de discurso anonimato na internet, representações de valoração, sobretudo, negativa. Destacamos o valor positivo apenas no trecho sublinhado em [3] e o valor negativo nos trechos em itálico em [1] e [2]. Vale destacar, no entanto, que, diferentemente do que ocorre na R1, em R2 o produtor remete ao tema anonimato na internet ao utilizar as expressões nominais "mundo on line, anônimos e internete", e apenas no trecho [2] aborda diretamente o tema central ao utilizar a expressão nominal "anonimato na web" - em negrito no trecho. Essa observação se confirma no desenvolvimento do texto, em que podemos observar a ênfase dada aos temas "homem", "lei" e "liberdade", o que mostra um deslize temático.

De toda forma, mesmo que de maneira indireta, há no texto representações construídas para o objeto de discurso anonimato na internet, para as quais o produtor recorre a ancoragens nos contextos imediato e mais amplo, como veremos a seguir.

No trecho [1], no destaque em itálico, o produtor remete a "anonimato na internet" ao 
construir a representação para "internet", afirmando que essa se constitui por homens não identificados - anônimos - que se utilizam de sua condição para causar danos. As pistas de sentido que o produtor oferece para evocar o tema central proposto são as expressões nominais "anônimos" e "mundo on line". O produtor elabora, assim, mesmo que indiretamente, uma representação para o objeto de discurso anonimato na internet como algo nocivo, capaz de causar danos aos outros, atribuindo-lhe valoração negativa.

Observamos, ainda, que para essa elaboração, o produtor recorre a dados do contexto imediato, o artigo de opinião, em que o jornalista cita fatos que ocorrem no mundo digital, tais como estelionato de opiniões e sites e blogs feitos para enxovalhar a honra alheia. Vale destacar, ainda nesse trecho, a presença do objeto de discurso "lei" evocado na predicação "sem serem devidamente punidos", que o produtor atribui aos sujeitos anônimos. As expressões nominais "anônimos" e "danos ao próximo" funcionam como pistas de sentido para o interlocutor inferir o posicionamento desfavorável do produtor relativo ao tema proposto para a redação.

No trecho [2], o único que aborda diretamente o anonimato na internet, a representação construída pelo produtor para o tema central, apresenta-o como algo que torna o homem um déspota, conferindo-lhe valoração negativa. Para elaborar essa representação, o produtor recorre a dados do contexto mais amplo, sua bagagem sociocultural e conhecimentos do âmbito da filosofia. No entanto, o produtor não oferece pistas de sentido suficientes para o interlocutor, embora cite nomes de filósofos no texto e a sua concepção - dos filósofos - sobre as leis e acerca do caráter do homem.

Assim, cria espaços lacunares que devem ser preenchidos pelo interlocutor, exigindo mais de seus conhecimentos e de sua bagagem sociocultural, para que possa realizar as inferências necessárias para a produção de sentidos. Destacamos, ainda, que essa representação do anonimato na internet elaborada pelo produtor ancora-se nas representações construídas no texto para os outros temas recorrentes "lei" e "homem".

Nesse momento, mais uma vez, o produtor retoma a ideia que vem sendo construída no universo discursivo do texto para a representação de anonimato na internet, a saber: na internet há liberdade sem responsabilidade e os anônimos realizam ações danosas sem serem punidos. Essa elaboração confirma que a argumentação do produtor está centrada na construção da representação de outros temas como "homem", "lei" e "liberdade", reiterando, assim, a sua relevância no desenvolvimento do texto e confirmando o deslize temático, o que fragiliza a redação no atendimento à proposta.

O trecho [3], o único que traz uma valoração positiva ao tema central, na realidade faz menção ao qual de forma indireta, pois o objeto de discurso para o qual o produtor constrói a representação é a internet, apresentando-a como uma "ferramenta" que possibilita a realização efetiva do anonimato. A representação construída pelo produtor para "internet" como algo benéfico, com capacidade de trazer ao homem integração e liberdade, remete ao contexto mais amplo, sociocultural e a seus conhecimentos sobre a rapidez e o alcance da internet para a divulgação de ideias e para a troca de informações entre pessoas, os quais são compartilhados por usuários da rede. As expressões nominais "integração" e "liberdade" funcionam como pistas de sentido. Assim, possibilita a seu interlocutor lançar mão de seus conhecimentos e de sua bagagem sociocultural, para realizar as inferências necessárias para a produção de sentidos, numa troca produtiva de interação que explicita uma negociação de sentidos.

Podemos observar, na tratativa dada ao tema pelo produtor, nesses trechos, uma tendência a se posicionar desfavoravelmente em relação ao anonimato na internet. Essa dis- 
posição será confirmada no desenvolvimento do texto, pois o produtor destaca a valoração positiva apenas sobre a internet, no trecho [3], em uma evocação ao tema central, apenas para afirmar, em seguida, que o uso responsável dessa ferramenta não ocorre.

A construção da representação do objeto de discurso anonimato na internet, elaborada indiretamente no texto, aponta para o fato de que o produtor, para estabelecer o seu posicionamento desfavorável frente ao tema e orientar a sua argumentação, lança mão de dados do contexto mais amplo, tanto as suas vivências e os seus conhecimentos, quanto os de seu interlocutor, como também a dados do contexto imediato, como é o caso do artigo de opinião, componente de referência na proposta do exame de vestibular, acessivel a ambos.

Ao propor a ancoragem no contexto mais amplo, no entanto, nem sempre deixa pistas de sentido suficientes a seu interlocutor. É o que ocorre ao remeter a conhecimentos do âmbito da filosofia, história e política, recorrendo a nomes de filósofos e conceitos. Nesse caso, no trecho [2], apenas faz citações, sem oferecer outras pistas de sentidos para essa ancoragem. Verificamos, portanto, que o produtor deixa espaços lacunares e nem sempre colabora para que o interlocutor realize as inferências necessárias para a produção de sentidos.

Além disso, como ressaltamos, o tema central "anonimato na internet" se dilui no texto em relação às presenças marcantes, principalmente, dos temas "homem", "lei" e "liberdade", retomados constantemente no desenvolvimento do texto e utilizados para construir a representação do tema proposto no exame.

Sustentamos, portanto, que embora o produtor construa indiretamente uma representação ao anonimato na internet, a qual evidencia o seu posicionamento desfavorável frente a esse tema central, o seu texto sofre um deslize temático. Além disso, o produtor nem sempre consegue estabelecer uma interlocução colaborativa com o seu leitor, por propor ancoragens no contexto mais amplo sem deixar pistas de sentido suficientes que permitam a negociação na interação para a produção de sentidos, além de não desenvolver uma orientação argumentativa coerente, em torno do tema central. É fato que o produtor viabiliza um projeto de dizer - "[...] o surgimento da internet impõe que as leis se renovem para limitar e responsabilizar a atuação do homem, defendendo assim, a liberdade individual de todos [...]" -, porém, pelos pontos elencados na análise, atende à proposta do exame de vestibular de maneira não bem-sucedida.

\section{Considerações finais}

Assumimos, neste trabalho, respaldados pela fundamentação teórica apresentada, que a construção de objetos de discurso e as suas representações implica processos de ancoragem que remetem a dados de contextos, imediato e mais amplo, e depende de pistas expressas na superfície textual para a produção de sentidos.

Desse modo, podemos aferir que nos processos de ancoragem está implicada a participação colaborativa do interlocutor que depende das pistas oferecidas pelo produtor e do balizamento que este último faz entre o que precisa estar implícito e o que pode ser inferido pelo interlocutor.

Acreditamos ser esse um aspecto a trabalhar, nas atividades de escrita destinadas a produtores ainda não proficientes, de forma a lhes mostrar que tornar acessivel a ancoragem nos contextos depende de se alcançar o equilíbrio entre implícitos e explícitos, bem como de deixar pistas para que se instaure uma interação mais colaborativa com o seu interlocutor, o que amplia as possibilidades tanto de produzir quanto de atribuir sentidos no/ao texto.

Percebemos, ainda, nas análises, que as projeções realizadas pelo produtor, ainda não proficiente, em relação a um interlocutor proficiente interferem, por um lado, de maneira positiva, 
no que concerne ao compartilhamento de suas vivências e dos conhecimentos socioculturais envolvidos; e, por outro, de maneira negativa, no que diz respeito a superestimar os conhecimentos de seu interlocutor e não deixar pistas suficientes para que este realize as inferências necessárias para a produção de sentidos.

Além disso, as representações construídas para o objeto de discurso, tema central da redação, à medida que the atribuem uma valoração, positiva ou negativa, colaboram para estabelecer a exposição do posicionamento do produtor frente ao tema proposto, apontam para a direção que a argumentação tomará no texto, além de viabilizar um projeto de dizer e o atendimento a uma dada proposta.

Acreditamos, adaptando para a produção escrita as palavras de Geraldi (2013, p. 112-113, grifos nossos) para a leitura, que

[...] trata-se agora de reconstruir, em face da produção escrita, a caminhada interpretativa do produtor: descobrir por que um dado sentido foi proposto, a partir das pistas contextuais fornecidas no texto. Isso significa se perguntar, no mínimo, que variáveis sociais, culturais e linguísticas foram acionadas pelo produtor, ainda não proficiente, para produzir os sentidos que produziu. Isso significa, ainda, dar atenção ao fato de que a produção escrita é uma forma de diálogo. É dar às palavras do produtor, ainda não proficiente, em uma atividade responsiva, a atenção que essa palavra merece, tendo em vista o desenvolvimento da proficiência escritora no nível básico da educação.

Assentimos, portanto, que, ao escrever, todo produtor é instado a pensar no uso da língua de maneira consciente para construir representações do mundo, ou seja, para construir "[...] versões da realidade que submete à aceitação do outro [...]" (CAVALCANTE; CUSTÓDIO FILHO; BRITO, 2014, p. 41). Relacionamos essa afirmação ao postulado de Olson (1997, p. 34), para quem o domínio da escrita implica saber
"[...] agir sobre a linguagem e pensar sobre ela, sobre o mundo e sobre nós mesmos [...]".

Acreditamos, enfim, que a escrita pressupõe sempre um projeto de dizer por parte do produtor de texto, mesmo ainda não proficiente, quando este se arrisca a representar o mundo por meio da linguagem. Neste trabalho, procuramos indicar novas possibilidades no tocante ao ensino e aprendizagem da escrita, sobretudo em relação ao desenvolvimento da proficiência escritora, contribuindo para que os docentes possam atuar como interlocutores colaborativos, mediando os processos de produção escrita, para que os alunos se tornem cada vez mais seguros de seus projetos de dizer e possam viabilizá-los de maneira bem-sucedida.

\section{Referências}

ADAM, J.-M. A linguística textual: introdução à análise textual dos discursos. São Paulo: Cortez, 2008.

BAKHTIN, M. M. Os gêneros do discurso. In: Estética da criação verbal. 3. ed. São Paulo: Martins Fontes, 2000.

BAZERMAN, C. Gênero, agência e escrita. São Paulo: Cortez, 2006.

BENTES, A. C.; REZENDE, R. C. Texto: conceitos, questões e fronteiras (con)textuais. In: SIGNORINI, I. (Org.). (Re)discutindo texto, gênero e discurso. São Paulo: Parábola, 2008.

BRASIL. Ministério da Educação. Secretaria do Ensino Fundamental. Parâmetros curriculares nacionais - terceiro e quarto ciclos do Ensino Fundamental - Língua Portuguesa. v. 2. Brasília, DF, 1998.

CAVALCANTE, M. M.; CUSTÓDIO FILHO, V.; BRITO, M. A. P. Coerência, referenciação e ensino. São Paulo: Cortez, 2014.

CAVALCANTE, M. M. et al. Dimensões textuais nas perspectivas sociocognitiva e interacional. In: BENTES, A. C.; LEITE, M. Q. (Org.). Linguística de texto e análise da conversação: panorama das pesquisas no Brasil. São Paulo: Cortez, 2010. 
GOMES-SANTOS, S. N. et al. A contribuição da(s) teoria(s) do texto para o ensino. In: BENTES, A. C.; LEITE, M. Q. (Org.). Linguística de texto e análise da conversação: panorama das pesquisas no Brasil. São Paulo: Cortez, 2010.

HANKS, W. F. O que é contexto. In.: BENTES, A. C. REZENDE, R. C.; MACHADO, M. A. R. (Org.). Língua como prática social: das relações entre língua, cultura e sociedade a partir de Bourdieu e Bakhtin. São Paulo: Cortez, 2008.

$\mathrm{KOCH}, \mathrm{I}$. G. V. Desvendando os segredos do texto. São Paulo: Contexto, 2003.

.; CUNHA-LIMA, M. L. Do cognitivismo ao sociocognitivismo. In: MUSSALIM, F.; BENTES, A. C. (Org.). Introdução à linguística, fundamentos epistemológicos. São Paulo: Cortez, 2011.

KOCH, I. G. V.; MORATO, E. M.; BENTES, A. C. Ainda o contexto: algumas considerações sobre as relações entre contexto, cognição e práticas sociais na obra de Teun van Dijk. Revista Latinoamericana de Estudios Del Discurso. Colômbia v. 11, n. 1, p. 79-92, 2011.

MARCUSCHI, L. A. Gêneros textuais: configuração, dinamicidade e circulação. In: KARWOSKI, A. M.; GAYDECZKA, B.; BRITO, K. $S$. (Org.). Gêneros textuais, reflexões e ensino. São Paulo: Parábola, 2011.

Gêneros textuais: definição e funcionalidade. In: DIONÍSIO, A. P.; MACHADO, A. R.;
BEZERRA, M. A. (Org.). Gêneros textuais e ensino. São Paulo: Parábola, 2010.

Produção textual, análise de gêneros e compreensão. São Paulo: Parábola, 2008.

Da fala para a escrita: atividades de retextualização. São Paulo: Cortez, 2000.

MORATO, E. M. O interacionismo no campo linguístico. In: MUSSALIM, F.; BENTES, A. C. (Org.). Introdução à linguística - fundamentos epistemológicos. São Paulo: Cortez, 2011.

OLSON, D. R. O mundo no papel - as implicações conceituais e cognitivas da leitura e da escrita. São Paulo: Ática, 1997.

PILAR, J. A redação de vestibular como gênero. In: MEURER, J. L.; MOTTA-ROTH, D. (Org.). Gêneros textuais. Bauru, SP: Edusc, 2002.

ROJO, R.; BARBOSA, J. P. Hipermodernidade, multiletramentos e gêneros discursivos. São Paulo: Parábola, 2015.

SCHNEUWLY, B.; DOLZ, J. Os gêneros escolares - das práticas de linguagem aos objetos de ensino. In: SCHNEUWLY, B. et al. Gêneros orais e escritos na escola. Trad. Roxane Rojo; Glaís Sales Cordeiro. São Paulo: Mercado de Letras, 2004.

VAN DIJK, T. A. Discurso e contexto: uma abordagem sociocognitiva. São Paulo: Contexto, 2012. 